\title{
Um estudo da experiência dos usuários de Internet banking de um banco público brasileiro
}

\author{
Thiago Hellen Oliveira da Silva \\ Universidade Federal do Ceará \\ Russas, Ceará, Brasil \\ thiagoo360@alu.ufc.br
}

\author{
Marília Soares Mendes \\ Universidade Federal do Ceará \\ Russas, Ceará, Brasil \\ marilia.mendes@ufc.br
}

\author{
Jeferson da Silva Juliani \\ Universidade Federal do Ceará \\ Russas, Ceará, Brasil \\ jeferson.engsoftware@alu.ufc.br
}

\author{
Carlos Rosemberg Maia de Carvalho \\ Fortaleza, Ceará, Brasil \\ berg@carlosrosemberg.com
}

\begin{abstract}
Banking systems have been a frequent concern between customers and companies, since the number of financial transactions carried out by the Internet has increased considerably. This study investigated the experience of internet banking users of a Brazilian bank. Techniques such as interviews, access log analysis, user journeys and usability testing were applied to identify the elements of the user experience using a generic model. From the studies carried out, it was verified that the characteristic users of the service had difficulty or are unable to use all the essential services of internet banking and are necessary design improvements of current interface.
\end{abstract}

\section{Author Keywords}

Internet banking; mobile; evaluation; UX; usability.

\section{ACM Classification Keywords}

H.5.m. Information Interfaces and Presentation (e.g. HCI): Miscellaneous

\section{INTRODUÇÃO}

Apesar da principal finalidade de uso da internet ter sido a comunicação online [5], aplicativos de internet banking possuem representatividade de $10 \%$ entre os preferidos dos brasileiros [2]. Em [5] foi observado que o canal preferido para uso de serviços bancários no Brasil é o celular (34\%), seguido do computador (23\%). No entanto, apenas $5 \%$ das pessoas dos países desenvolvidos possuem habilidades para realizar tarefas complexas com um computador [6]. Da mesma forma, apenas um terço das pessoas destes países conseguem completar tarefas de complexidade mediana [6]. A partir destes dados, [6] concluem que, no geral, os sistemas ainda são

Permission to make digital or hard copies of all or part of this work for personal or classroom use is granted without fee provided that copies are not made or distributed for profit or commercial advantage and that copies bear this notice and the full citation on the first page. To copy otherwise, or republish, to post on servers or to redistribute to lists, requires prior specific permission and/or a fee. IHC'18, Brazilian Symposium on Human Factors in Computing Systems. October 22-26, 2018, Belem, PA, Brazil. Copyright 2018 SBC. ISBN XXX-XX-XXXX-XXX-X (pendrive) difíceis de usar por pessoas que não possuem afinidade tecnológica $(95 \%)$.

Neste contexto, um banco brasileiro procurou os autores deste artigo a fim de conhecer a experiência dos usuários em seu sistema de internet banking (nas versões desktop e aplicativo móvel). Por questões de sigilo contratual, neste estudo o banco será chamado de Banco X $(\mathrm{BX})$.

A Experiência do Usuário (User eXperience, UX) é definida como percepções e respostas dos usuários, resultantes do uso de um produto, sistema ou serviço [9]. Segundo [7] a UX engloba todos os aspectos da interação do usuário final com a empresa, seus serviços e seus produtos. Este trabalho apresenta um estudo da UX de internet banking, focando nos aspectos da interação do usuário com o BX. O estudo da UX foi realizado em um Modelo genérico de Experiência do usuário denominado de MEX [4].

Os autores deste trabalho aplicaram técnicas de: estudo dos usuários; estudo dos softwares mobile e web do BX; e testes com os usuários. Alguns dos resultados obtidos com este trabalho foram: identificação dos elementos da UX, identificação e uso de perfis representativos dos usuários, gerados por uma multiplicidade de dados, e problemas relacionados à experiência dos usuários com o BX, como, por exemplo, a dificuldade de acesso mobile após a abertura de uma conta.

\section{MODELO MEX}

A metodologia deste trabalho foi baseada no Modelo genérico de EXperiência do usuário (MEX) [4]. O MEX fornece uma estrutura conceitual para a compreensão de experiências, dividindo-a em 6 elementos de alto nível e estabelecendo relações entre eles.

Os elementos que compõem o modelo são (Figura 1) [4]: individuo; atividade; contexto; artefatos; interação; e momentos. O indivíduo é o usuário e todos os fatores que o envolve (culturais, sociais, pessoais e psicológicos). A atividade se refere às ações ligadas ao objetivo do usuário que justificam a experiência e delimitam seu escopo. $O$ contexto se refere a situação e ambientes nos quais a interação acontece. Os arte- 
fatos podem ser tanto o objeto principal (com o qual o usuario interage diretamente) quanto os que estao a sua volta e interferem de alguma forma nessa interacao. A interação é troca de estímulos que define como os artefatos se relacionam. Momentos se referem a como a experiência é desenvolvida.

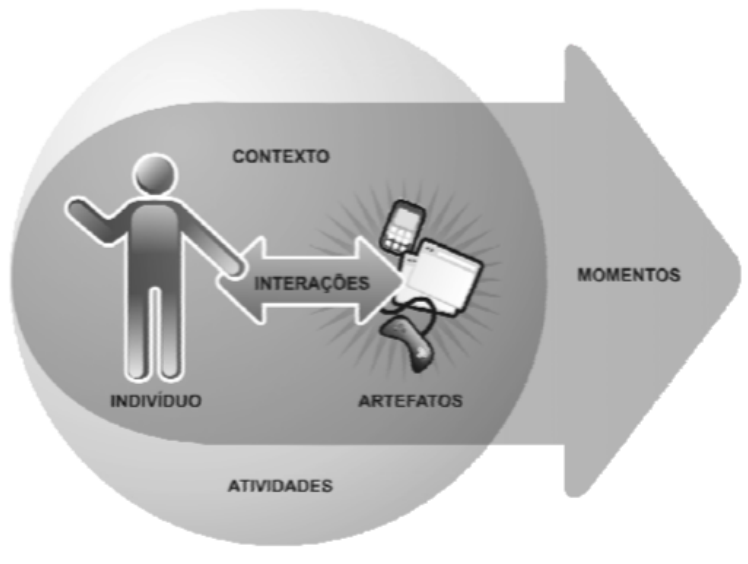

Figura 1. MEX - Modelo genérico da experiência do usuário

Focar em tais elementos envolve responder às seguintes questões [4]:

1. indivíduo: que informações do indivíduo são relevantes para que se possa entende-lo?

2. atividades: quais as principais atividades que os usuários executarão, baseado em suas necessidades?

3. contexto: quais as principais situações e características dos ambientes que a experiência pode ocorrer?

4. artefatos: que artefatos são importantes para a experiência? que atributos devem ser levantados?

5. interação: quais os tipos de interação entre o indivíduo e os artefatos?

6. momentos: que aspectos dos momentos influenciam a experiência?

\section{INVESTIGAÇÃO}

Para identificar os 6 elementos da UX destacados no MEX, este estudo foi realizado em 3 etapas: 1) estudo dos usuários (focando nos elementos: indivíduo e contexto); 2) estudo dos softwares mobile e web do BX (focando nos elementos: atividade e artefatos); e 3) testes com os usuários (focando nos elementos: interação e momentos).

\section{Estudo dos usuários}

Foram realizadas entrevistas internas e externas. As entrevistas internas foram realizadas com funcionários do departamento de comunicação e marketing do BX, para saber quais segmentações (perfis de cliente) são predominantes entre todos os clientes. Foram identificados três segmentos: empreendedores, caracterizado por clientes de microcrédito ou que possuem pequenas, médias ou grandes empresas; colaboradores, que não são clientes diretos do banco, mas são usuários de seus sistemas, pois trabalham a serviço de uma empresa que é cliente do BX; e pessoas físicas, segmentação onde há uma parcela significativa de usuários que trabalham no próprio banco (dado o seu tamanho). Como o objetivo do banco não é prestar serviços principalmente aos seus funcionários, a segmentação pessoas físicas não foi considerada para esse estudo.

Em seguida, foram realizadas entrevistas externas com o propósito de detalhar cada segmento. A entrevista foi realizada com 11 pessoas, sendo 6 mulheres e 5 homens residentes na capital ou no interior de um estado brasileiro, com faixa etária de 22 a 65 anos. Nem todos os participantes são clientes do BX.

Em geral os participantes relataram que o seu dia-a-dia é muito corrido, pois têm muita coisa para fazer dentro da empresa e, muitas vezes, não têm um ajudante. Foi relatado também que os aplicativos mais usados por eles, nos últimos dias, foram de banco, ferramentas e comunicação. Além disso, os serviços mais utilizados por eles, nos dias anteriores à entrevista, foram de pagamentos e verificação do saldo em conta. Os participantes relataram diversas situações em que tiveram problemas com o seu banco. Os mais relatados foram: sistema fora do ar, erro ao realizar transferência, falta de aviso sobre o limite próximo de ser atingido, pagamento não exibido no extrato, processo burocrático para criar uma conta. E por fim, muitos deles relataram que os aplicativos poderiam ser mais simples e mais fáceis de usar.

\section{Estudo dos softwares}

Foi realizada uma análise do $\log$ de acesso à versão web e mobile do internet banking BX para investigar as funcionalidades mais utilizadas. Dentre elas, destacam-se: emissão de saldo e extrato de conta corrente; pagamento de boleto bancário; e, transferência de valores.

Também foi observado qual a primeira ação que os usuários realizam ao acessar o internet banking. Esta ação pode ser considerada como a intenção de uso, já que é a primeira a ser realizada ao acessar o sistema. Dentre elas, destacam-se: extrato da conta; saldo em conta; transferência de valores; e pagamento de boletos. Dessa forma, pode-se observar que existe um conjunto de ações prioritárias, como: saldo, extrato, pagamentos e transferências; pois elas estão dentre as mais utilizadas e as que são realizadas logo ao acessar o internet banking.

A técnica Jornada do usuário [10], foi aplicada com o objetivo de identificar problemas e artefatos sob o ponto de vista do cliente, durante seu relacionamento com o BX. A jornada foi realizada por um dos autores e é relatada a seguir.

"Primeiro, eu realizei uma coleta de informações a partir da busca no site do BX, pela documentação necessária para abrir uma conta. Em seguida, fui até uma agência do banco e descobri que lá só se abria conta poupança. Realizei o preenchimento do cadastro e o atendente do banco me pediu para que constantemente entrasse em contato para saber se o meu cadastro havia sido efetivamente efetuado e aprovado. Após o cadastro, foram me repassadas instruções de login do Internet Banking, logo em seguida, tentei acessá-lo dentro da agência utilizando o aplicativo mobile e ao inserir as informações, o aplicativo apenas exibiu a mensagem "Por favor, aguarde”. Após várias tentativas sem sucesso, consegui acessar minha conta pelo aplicativo, apenas após aceitar o 
contrato de prestação de serviço no internet banking na web. Realizei uma tentativa sem sucesso de uma transferência de valores. Com o propósito de solucionar o problema, entrei em contato com o serviço de atendimento ao consumidor, $e$ descobri que se tratava de um problema com o meu cartão de segurança (eu precisava ativá-lo). Após a resolução do problema e a realização da transferência, enviei o comprovante gerado para fora do aplicativo. Por fim, utilizei o aplicativo rotineiramente para verificar meu saldo e emitir extratos.".

A partir da Jornada do Usuário realizada, percebeu-se que para um cliente novo, falta uma integração mais fluida e conectada entre internet banking e a agência física, pois o cliente não recebe orientações sobre o que ele deve fazer para conseguir efetivamente acessar o serviço online e realizar suas transações financeiras. Também foi constatado que não é possível realizar o primeiro acesso a partir do aplicativo mobile, pois a etapa de aceitação do contrato de prestação de serviço é exibida somente na versão web (no desktop).

\section{Testes com usuários}

Nesta etapa, foi realizado um Teste de Usabilidade [7] por três especialistas em IHC e dois estudantes. Os objetivos foram investigar: a) quais os principais problemas ao se usar o Internet banking (mobile e web); b) o quão efetivamente as pessoas executam as tarefas mais comuns; e, c) qual a percepção geral de facilidade uso da ferramenta.

$\mathrm{O}$ teste foi executado na capital e interior de um estado do Brasil, e foram recrutadas 11 pessoas voluntariamente, com o perfil similar aos perfis identificados no estudo dos usuários. Das 11 pessoas recrutadas, 7 tinham o perfil de pequeno empreendedor e 4 o perfil de colaborador. Tais pessoas foram recrutadas após um mapeamento de pequenas e médias empresas das cidades, por terem disponibilidade e o perfil desejado para o teste.

No cenário definido para a realização do teste, o participante deveria supor estar utilizando o internet banking em um dia típico. A plataforma utilizada foi definida a partir do estudo dos usuários: para os participantes com perfil de pequeno empreendedor foi utilizada a plataforma mobile; e para os participantes com perfil de colaborador, foi utilizada a plataforma web. Para a versão mobile, foram utilizados os sistemas operacionais Android e iOS.

Cada sessão de teste (Figura 2) foi realizada envolvendo quatro pessoas: um participante, um facilitador, um observador e uma pessoa responsável por gravar o áudio e vídeo das sessões. O facilitador era responsável por conduzir o teste e o observador, por realizar anotações relevantes. Em cada sessão de teste foi solicitada ao participante, a autorização para gravação de áudio e vídeo, com a assinatura de um termo de consentimento.

Foram testadas as funcionalidades: acessar conta, consultar saldo, consultar extrato, fazer transferência e enviar comprovante. Dessa forma, os participantes tiveram que: a) abrir/acessar o aplicativo/site do internet banking e descrever o que vê; b) acessar a conta usando as credenciais repassadas e descrição do que vê; c) descobrir quanto dinheiro tem em conta; d) verificar se houve alguma movimentação recente na

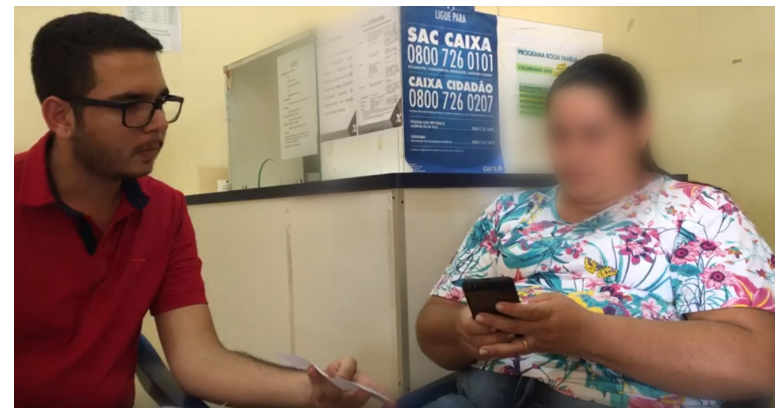

Figura 2. Execução do teste de usabilidade

conta e descrever o que vê; e) transferir R \$10,00 para uma conta informada; e por fim, f) retornar à tela inicial, e enviar uma comprovação da transferência realizada para um número de telefone ou e-mail informado.

Após a realização de cada sessão de teste, foi aplicado um questionário para investigar a satisfação dos usuários com o sistema. Neste estudo, foi utilizado o questionário SUS (System Usability Scale) [1]. O questionário possui 10 afirmações e para cada uma delas, o participante deveria responder dentre as opções: 1- discordo fortemente; 2- discordo; 3- não discordo nem concordo; 4- concordo; ou 5- concordo fortemente.

Para analisar os resultados obtidos pelo questionário, é calculada a sua pontuação de acordo com as respostas e o número sequencial da questão: as questões de ordem ímpar, subtraise 1 da resposta do participante; para questões de ordem par, subtrai-se a resposta do participante de 5; por fim, multiplica o resultado de cada questão por 2.5 para obter a pontuação SUS [1].

Para cada participante foi calculada a pontuação SUS de acordo com as suas respostas. Em seguida, foi gerada a pontuação média para cada plataforma, obtendo como resultado 58.50 pontos para a versão mobile e 60 pontos para a versão web.

Em [8], é definido que uma pontuação SUS acima de 68 pontos é considerada acima da média, e sistemas que apresentam graves problemas de interface e/ou interação possuem uma pontuação abaixo desse número. Dessa forma, de acordo com a média SUS obtida, observa-se que o internet banking BX em sua versão web e mobile, possuem problemas graves de interface e/ou interação.

\section{RESULTADOS}

Nesta seção são respondidas as questões levantadas, identificando os 6 elementos da UX do modelo MEX.

A partir do estudo dos usuários, foram definidas duas personas [3] (indivíduo) do internet banking, apresentadas a seguir.

Persona do perfil pequeno empreendedor: Marcos é microempresário, tem 34 anos e possui ensino médio. Ele é dono de um mercadinho que cresce a todo o vapor, fruto de sua garra. Incansável, pega no batente cedo e faz de tudo um pouco. 
Em seu dia-a-dia, sempre o atrapalha perder tempo resolvendo problemas em seu banco, odeia burocracia e coisas complicadas de se fazer. Marcos gosta de informação rápida e confiável na palma da mão, já que se locomove o tempo todo e não tem tempo de ficar no computador. Quer sempre poder contar com parceiros de forma rápida e confiável.

Persona do perfil colaborador: Joana é gerente financeira, tem 37 anos e possui ensino superior. Ela cuida das finanças de uma imobiliária de médio porte. Organizada e atenciosa aos detalhes, é especialista em resolver vários problemas ao mesmo tempo e não deixa que sua rotina afete a qualidade de seu trabalho. Atrapalha-se muito quando se depara com informações imprecisas e odeia surpresas indesejadas, pois depende muito de planejamento. Joana não gosta de coisas complicadas para fazer ou entender e gostaria muito de prever seu planejamento e poder contar com alguém rapidamente quando algo de errado acontece.

As principais atividades que os usuários executam no internet banking são: consulta do saldo, extrato da conta, transferência de valores e pagamento de boletos. Tais atividades foram definidas a partir da análise do log de acesso. As tarefas mais importantes são aquelas que envolvem movimentação de dinheiro.

A UX pode ocorrer em dois contextos: em um escritório, durante a jornada de trabalho de um colaborador, usando a versão web; ou em qualquer lugar, quando acessado pelo empreendedor, em um dispositivo móvel. Tais contextos foram identificados com a técnica jornada do usuário e com a realização de entrevistas no estudo dos usuários. Os artefatos mais importantes para a UX do usuário do BX são: telefone celular, computador e o cartão de segurança.

A interação do usuário foi observada na realização do Teste de Usabilidade e na jornada do usuário. Durante a realização do Teste de Usabilidade, alguns participantes (recrutados a partir dos perfis identificados) não souberam como usar o cartão de segurança (item essencial para realizar movimentações financeiras no internet banking), confundiram o número, ou não entenderam que deveriam utilizálo. Alguns usuários também não conseguiram encontrar facilmente os itens pelo menu ou confundiram a forma de utilizar algumas funcionalidades, tanto na versão web como na mobile.

O uso de mais de uma técnica possibilitou captar os três momentos da UX: antes, durante e o depois. A jornada do usuário captou o momento inicial (antes do uso), quando o usuário não conseguiu acessar o aplicativo na versão mobile, pois era necessário aceitar o contrato de prestação de serviço na versão web. O teste com usuários captou o momento de utilização do aplicativo (durante o uso) na versão mobile, quando um usuário não conseguiu ativar seu cartão de segurança. Após os testes com os usuários (depois do uso), os usuários relataram dificuldades de uso e problemas do sistema na aplicação do questionário SUS.

\section{CONCLUSÃO E TRABALHOS FUTUROS}

Este trabalho teve como objetivo investigar a UX do internet banking de um banco brasileiro. Alguns dos resultados obti- dos foram: identificação dos elementos da UX, identificação e uso de perfis representativos dos usuários e problemas relacionados à UX, como a dificuldade de acesso mobile, após a abertura de uma conta.

Dado os problemas identificados, atualmente está sendo realizada a reformulação de design dos sistemas de internet banking BX. Como trabalhos futuros será feita uma análise comparativa da UX entre o antes e depois, do sistema com um novo design.

Além dos aplicativos de internet banking, os bancos têm apoiado seus clientes com o uso de páginas em sistemas sociais, como o Facebook e o Twitter. Bancos como o Banco do Brasil, Caixa Econômica, etc., estão usando páginas em redes sociais para ter um contato com seus clientes. $\mathrm{O}$ apoio funciona da seguinte forma: os clientes postam mensagens sobre os serviços prestados (dúvidas, críticas) e o suporte dos bancos tentam resolver. Em uma análise prévia, realizada pelos autores deste artigo, foram observados nas mensagens dos clientes relatos de: problemas de usabilidade nos aplicativos, experiência de uso nos serviços oferecidos; e ainda divulgação dos dados pessoais pelos usuários. Um outro trabalho futuro é investigar, a partir de mensagens postadas em páginas de sistemas bancários, os aplicativos, serviço e segurança dos usuários em sistemas bancários.

\section{REFERENCIAS}

1. Brooke, J., et al. Sus-a quick and dirty usability scale. Usability evaluation in industry 189, 194 (1996), 4-7.

2. Conecta, I. Whatsapp é o aplicativo mais usado pelos internautas brasileiros, 2015. Disponível em: https://goo.gl/ScT1pt. Acesso em 10 de jun de 2018.

3. Cooper, A., et al. The inmates are running the asylum:[Why high-tech products drive us crazy and how to restore the sanity]. Sams Indianapolis, 2004.

4. de Carvalho, C. R. M. Mex experience boards: a set of agile tools for user experience design. In Proceedings of the IX Symposium on Human Factors in Computing Systems, Brazilian Computer Society (2010), 213-216.

5. IBGE. Acesso à internet e à televisão e posse de telefone móvel celular para uso pessoal, 2016. Disponível em: https ://goo.gl/CwcyEq. Acesso em 10 de jun de 2018.

6. NNGROUP. The distribution of users' computer skills: Worse than you think, 2016. Disponível em: https://goo.gl/uvMc8b. Acesso em 01 de jun de 2018.

7. Rogers, Y., Sharp, H., Preece, J., and Gasparini, I. Design de interação: além da interação humano-computador. Bookman, 2013.

8. Sauro, J. Measuring usability with the system usability scale (sus), 2011. Disponível em: https://goo.gl/zQeev7. Acesso em 04 de abr de 2018.

9. Standardization, I. Ergonomics of human-system interaction: Part 210: Human-centred design for interactive systems. iso 9241-210, 2010.

10. Vianna, M. Design thinking: inovação em negócios. Design Thinking, 2012. 